\title{
HIGHLY ACTIVATED CARBON ENTEROSORBENT MEDIATES THE SUPPRESSION OF PARANEOPLASTIC SYNDROME ASSOCIATED WITH LEWIS LUNG CARCINOMA IN MICE
}

\author{
V.V. Sarnatskaya ${ }^{1, *}$, L.A. Sakhno ${ }^{1}$, L.M. Paziuk', L.A. Yushko', N.K. Rodionova ${ }^{1}$, V.N. Maslenny ${ }^{1}$, \\ A.S. Sydorenko ${ }^{1}$, V.G. Nikolaev ${ }^{1}$ \\ ${ }^{1}$ R.E. Kavetsky Institute of Experimental Pathology, Oncology and Radiobiology, NAS of Ukraine, \\ Kyiv 03022, Ukraine \\ ${ }^{2}$ Department of Cytology, Histology and Developmental Biology, Institute of Biology, \\ Taras Shevchenko National University of Kyiv, Kyiv 03608, Ukraine
}

\begin{abstract}
Aim: To investigate the effect of enterosorption on the development of paraneoplastic syndrome in mice with Lewis lung carcinoma (LLC). Materials and Methods: The study was performed on male C57/BL6 mice with transplanted LLC. As an enterosorbent, highly activated powder fraction of HSGD was administered per os daily at a dose of $0.625 \mathrm{~g} / \mathrm{kg}$ for two weeks starting from the $7^{\text {th }}$ day after tumor cell transplantation. Analysis of hemo- and myelograms, morphological alterations in vital organs, the activities of catalase and superoxide dismutase, biochemical analysis of blood and quantitative analysis of hydroperoxides, malonic dialdehyde, advanced oxidation protein products was carried out by standard methods after completing the course of enterosorption. Ligand loading of blood plasma proteins was estimated by the method of differential scanning microcalorimetry. Results: Administration of enterosorbent resulted in inhibition of LLC growth and in nearly 2 -fold decrease of lung metastases number $(p<0.05)$. Activation of granulocytic line in the bone marrow with nearly 3-fold enhancement of mitotic activity took place after enterosorbent administration. Red cell lineage indices and bone marrow cellularity remained unaltered. After enterosorption session, the studied biochemical indices of peripheral blood evidenced on decreasing the endogenous intoxication and oxidative stress levels, improving the functional state of kidneys, increasing the resistance of erythrocyte membranes and lowering the ligand loading of blood plasma transport proteins. Morphological structure of kidneys and liver confirmed significant positive effect of enterosorption. The data of morphologic examination of gastric fundus, small intestine, and large bowel slides after 2-week administration of enterosorbent showed its high safety and proper evacuation from intestine. Conclusion: The two-week long enterosorption session in mice with LLC caused the suppression of tumor growth and metastasis, normalization of bone marrow hemopoiesis. Enterosorption exerted a positive influence on the structural-morphologic indexes and regenerative potential of kidneys and liver, mitigated manifestations of oxidative stress, decreased the level of endogenous intoxication, promoted deliganding of albumin molecule and deloading of erythrocyte membranes.
\end{abstract}

Key Words: paraneoplastic syndrome, Lewis lung carcinoma, enterosorption.

The motivation to use the method of enterosorption for treatment of mice with Lewis lung carcinoma (LLC) was based on multiple positive results of per os usage of carbon adsorbents for therapy of a number of pathologies including acute radiation sickness, chronic glomerulonephritis, biliary and portal cirrhosis, severe forms of leptospirosis, food allergy, psoriasis, acute enteric infections, idiopathic dilation cardiomyopathy, and chronic renal failure [1-9], as well as severe myelo-, nephro-, cardio- and gonadotoxic side effects of intense cancer chemotherapy [10,11].

All these reports evidenced on significant positive therapeutic pathomorphosis of mentioned pathologies under the influence of enterosorption, first of all, on acceleration of reparative processes in damaged organs and tissues.

Submitted: July 19, 2017.

*Correspondence: E-mail: vsnikavera@gmail.com Abbreviations used: AlkP - alkaline phosphatase; ALT - alanine transaminase; AOD - antioxidant defense; AOPP - advanced oxidation protein products; AST - aspartate transaminase; EGI - endogenous intoxication; GIT - gastrointestinal tract; G-SH - glutathione; HP - hydroperoxide; HSA - human serum albumin; LHP - lipid hydroperoxide; IMA - ischemia modified albumin; LLC - Lewis lung carcinoma; MDA malonic dialdehyde; MMWS - middle molecular weight substances; PNS - paraneoplastic syndrome; SOD - superoxide dismutase.
High regenerative potential of carbon enterosorbents demonstrates itself in pathologies of different etiology and points on an existence of some common elements in pathogenesis of these diseases which include, for example, the development of endogenous intoxication (EGI), oxidative stress, anemia, impaired excretory organs.

Malignant tumors exert systemic influence on an organism and therefore could cause the development of paraneoplastic syndrome (PNS) which could be represented by certain immune conflict between tumor and organism, complex changes of structure and function of some organs, the development of significant metabolic disorders. According to the newest data, a significant role in promotion of PNS manifestations belongs to proangiogenic factors produced at high level by malignant cells in vitro and in vivo [12]. Anemia is among the most crucial disorders caused by systemic influence of malignant tumor growth. By statistical data, anemia develops in nearly $30 \%$ of primary cancer patients [13], in $71 \%$ of patients with lung carcinoma (this cancer type is characterized by the highest rate of PNS development among all cancer types) [14], and in up to $90 \%$ of patients treated with chemotherapy [15]. Also, it has been shown that the risk of lethal outcome in the patients with anemia is by $65 \%$ higher than in the patients without anemia [16]. 
Severe EGI often observed in cancer patients could be caused by the products of tumor metabolism and biochemical disorders caused by the growth and mechanical action of the tumor [17]. Important role in the formation of EGI syndrome plays the dysfunction of natural mechanisms of detoxification [18]. Imbalance of metabolic processes at the background of decreased detoxification potential of an organism leads to "metabolic EGl" [19].

Presently it is accepted that EGI development could be significantly affected by oxidative stress via activation of free radicals and imbalanced rate of generation of compounds with antioxidant or prooxidant properties [20]. Prooxidants may serve as the mediators of inflammation, induce severe defects in activity of defensive antioxidant systems and their cofactors, and also exert negative influence on the state of different biologic compounds, including signaling molecules. An excessive generation of free radicals could be responsible for the development of hyperviscosity, hypercoagulation, dysfunction of endothelium and protein modification [21]. Free radicals could be involved in neoangiogenesis through activation of production of vascular growth factors in endothelial and mesothelial cells [22]. The damaging action of free radicals is directed on three types of targets: lipids, nucleic acids, and proteins. An action of reactive oxygen species could result in oxidation of amino acid residues and disturbed structure and function of the proteins. Hydroxyl radicals attacking protein molecules do not remain in free state but create the complexes with the proteins, which in turn become damaged and degraded by proteolytic enzymes [23]. For example, in the presence of hydroxyl radicals $\beta_{2}$-microglobulin becomes fragmented or polymerized that is evidenced by the methods of fluorometry and circular dichroism, demonstrating the disappearance of the fraction with molecular weight of $12 \mathrm{kDa}$ typical for $\beta_{2}$-microglobulin and appearance of a band of high molecular weight cross-linked proteins [24]. The large part of oxidized proteins are functionally inactive and more accessible for proteolysis, are capable to accumulate in different tissues, mediate oxidative damage of DNA, may serve as a source of free radicals and reduce the sources of cell antioxidants such as ascorbic acid and glutathione [25]. So, oxidized proteins could be not only "bystanders", but also the active participants of the process of free radical damage occurring in a body at different pathologic states.

The central place among transport proteins of blood is occupied by human serum albumin (HSA) which is presented in blood plasma at a concentration of 45$50 \mathrm{mg} / \mathrm{ml}$. As far as plasma volume yields at average three liters, liver synthesized nearly $3 \mathrm{~g}$ of this protein per day; its half-life is 19-20 days. Functions of albumin include the regulation of osmotic pressure and transport of many compounds of different chemical nature, including fatty acids, bile pigments, metabolites and toxins, medicinal preparations and poisons, and also ions of some metals such as copper, cobalt, aluminum, zinc, etc. [26]. While the major part of plasma copper is bound with ceruloplasmin, a natural antioxidant, HSA also possesses a tropism to ions of this metal, therefore some quantity of copper ions are in a complex with its molecule. At present time, there are multiple evidences on antioxidant activity of albumin [27]. This protein is capable to suppress generation of hydroxyl free radicals in the systems which contain copper ions and $\mathrm{H}_{2} \mathrm{O}_{2}$. While attacking, hydroxyl radicals disturb the molecular structure of albumin, however, they are caught by it and tightly retained in a safe bound state. In turn, the damaged albumin undergoes degradation by proteolytic enzymes, and its loss is quickly compensated by a newly synthesized portion of the protein. Potential targets for oxidants are sulfhydryl groups of the proteins, and in relation to albumin, an oxidation process utilizes its single free $\mathrm{SH}$-group at Cys 34 , with generation of sulfenic group [28].

An accumulation of toxic metabolites in a cancer patient's organism is promoted by dysfunction of natural excretory-evacuation systems [29, 30], as well as decreased activity of a number of enzymatic complexes responsible for neutralization of exo- or endotoxins [31]. Apart from this, in cancer patients there is observed the ligand overloading of cellular and humoral transport agents of blood and related malfunction of toxic metabolite transfer [32]. High level of EGI observed in cancer patients as well as powerful pro-regenerative potential of carbon enterosorbents, indicate a necessity to study an effectiveness and rationale for their usage in adjuvant therapy of cancer patients.

This work presents an evidence for correcting action of enterosorption toward hematologic indexes, morphologic and structural/functional parameters of natural excretory-evacuation and transport systems, including erythrocyte membranes and blood plasma serum albumin as well as some indexes of oxidative stress in mice with LLC.

\section{MATERIALS AND METHODS}

In the study, male C57/BL6 mice 2-2.5 months old weighting $18-23 \mathrm{~g}$ bred in the animal facility of Institute of Experimental Pathology, Oncology and Radiobiology of the NAS of Ukraine (Kyiv, Ukraine) were used. The research was performed in accordance with the rules of local committee on ethic aspects of work with experimental animals. LLC was used as experimental tumor model [33].

Experimental animals were randomized by weight, and distributed in 4 groups ( 11 mice per group): 1 ) intact animals; 2) mice with transplanted LLC (control group); 3) mice with transplanted LLC treated with enterosorbent (ES-group); 4) animals with transplanted LLC administered with water (through the probe) by the same schedule as ES-mice for an assessment of the effects of stress factors related to the placement of probe (SF-group).

Highly activated powder carbonic enterosorbent was prepared by grinding of microgranulated fraction 
(diameter $<0.25 \mathrm{~cm}$ ) of HSGD sorbent in multichannel grinding mill MCM-300 $\mathrm{H}$ at separator rotation speed of $60 \mathrm{~Hz}$.

Enterosorption has been performed daily for 2 weeks. Powdered high-disperse fraction of the sorbent was resuspended in $0.5 \mathrm{ml}$ of boiled water and administered orally through a probe, starting from day 7 after tumor cell transplantation. Total daily dose of enterosorbent was $0.625 \mathrm{~g} / \mathrm{kg}$ body mass. Mice from SF-group were administered with $0.5 \mathrm{ml}$ of boiled water.

To assess the effect of highly active powder carbon enterosorbent on gastrointestinal tract (GIT) mucosa, an additional group composed from 7 intact mice of the same weight was treated with enterosorbents at the same dosage and by analogous schedule.

Hemograms were analyzed by the method adapted for the study of blood cells of mice using the hematological analyzer "PCE 210" (ERMA, Japan).

The number and total volume of metastases in experimental animals were calculated using the method described earlier [34].

Bone marrow cells isolated from femoral bone of experimental animals were counted in hemocytometer by the method [35]. To study the myelograms, the smears were prepared and stained by Pappenheim. For evaluation of cellular composition of bone marrow, an analysis was performed in total haemopoiesis pools dependent on cell differentiation grade, namely: myeloid lineage: immature granulocytic cells - myeloblasts, neutrophilic and eosinophilic promyelocytes, myelocytes, metamyelocytes; mature granulocytes neutrophils and eosinophils banded or segmented; erythroid lineage: immature cells - erythroblasts, pronormocytes, basophilic normocytes, polychromatophilic or oxyphilic normocytes.

Mitotic activity was determined by the number of cells at the phase of mitosis ( 1000 cells of myelogram per calculation).

Analysis of morphological structure of GIT, liver, and kidneys of mice was performed after enterosorption session was finished. Animals were immediately decapitated, and biomaterials were fixed in $10 \%$ neutral formalin, then paraffin embedded tissue blocks were routinely prepared. 5-6 $\mu \mathrm{m}$ slides were stained with hematoxylin and eosin and examined by light microscopy. Microphotographs were done using System Microscope device with video camera Olympus BX 41 system, equipped with digital camera Camedia C-5050 zoom and Olympus DP 80 FT 3.2 software based on Pentium 4 computer with operation system Windows XP.

The quantity of generated hydroperoxides (HP) and malonic dialdehyde (MDA) were determined by the methods [36] and [37], respectively.

For quantitative evaluation of advanced oxidation protein products (AOPP) the method based on the reaction of interaction between potassium iodide, chloramine T and acetic acid was used. Optical density of reaction mixture was registered at the $340 \mathrm{~nm}$ wave length [38].
Concentration of ischemia modified albumin (IMA) was determined by the colorimetric method [39].

Concentrations of total protein, albumin, urea, uric acid, creatinine, alanine transaminase (ALT), aspartate transaminase (AST), alkaline phosphatase (AlkP) in blood were determined using test kits BioSystems. Osmotic resistance of erythrocytes was determined according to the method [40]. Complex-formation of albumin with vital dye methylene blue was assessed by the method [41].

The activities of catalase and superoxide dismutase (SOD) were determined by standard methods $[42,43]$.

To assess ligand loading of blood plasma proteins the method of differential scanning microcalorimetry was used. The blood plasma samples underwent thermal denaturation using apparatus DACM-4 (Pushchino, Russia) at the heating rate of $1^{\circ} \mathrm{C} / \mathrm{min}$.

Statistical analysis of the data has been performed using mathematical program for medico-biological statistics STATISTICA 6.0. Variation-statistical processing of the data was conducted using computer program Microsoft Excel 2007. For calculation and comparison of the reliability of the average values of the differences Student's $t$-criterion was used; the differences with probability not less than 95\% $(p<0.05)$ were considered significant.

\section{RESULTS AND DISCUSSION}

In our studies we used a previously created highly active carbon sorbent with spherical granulation HSGD-2 [44], which was grinded to get its powder form (average particle size is $\approx 2 \mu$ ). The fine carbon fraction is preferable because of a significantly larger external surface area compared to granules and, correspondingly, a higher sorption-kinetic potential, which was evaluated by adsorption of marker compounds under standard conditions [45]. Moreover, highly dispersed aqueous suspensions of powder enterosorbents greatly facilitate the process of their oral administration to small animals and make it practically non-traumatic.

The indexes of adsorption of major marker compounds by HSGD enterosorbent in the forms of spherical granules and powder are presented in Table 1.

It is necessary to note that observed differences between adsorption values of marker compounds depend not on those by absolute sorption capacity of the samples but on kinetic indexes predetermined by an availability of sorption pores which are higher in fine-disperse powder.

Table 1. Adsorption capacity of granulated and powdered HSGD-2 sorbent

\begin{tabular}{lccccc}
\hline \multicolumn{1}{c}{ Sample } & $\begin{array}{c}\text { Methylene } \\
\text { blue, } \mathrm{mg} / \mathrm{g}\end{array}$ & $\begin{array}{c}\text { Creat- } \\
\text { inine, } \\
\mathrm{mg} / \mathrm{g}\end{array}$ & $\begin{array}{c}\mathrm{B}_{12}, \\
\mathrm{mg} / \mathrm{g}\end{array}$ & $\begin{array}{c}\text { Bilirubin, } \\
\mathrm{mg} / \mathrm{g}\end{array}$ & $\begin{array}{c}\text { Total pro- } \\
\text { tein, } \mathrm{g} / \mathrm{g}\end{array}$ \\
\hline $\begin{array}{l}\text { HSGD-2 } \\
\mathrm{Y}=0.155 \mathrm{~g} / \mathrm{cm}^{3},\end{array}$ & 664.26 & 140.64 & 444.08 & 15.67 & 1.23 \\
$\begin{array}{l}\text { granules } \\
\text { HSGD-2 } \\
\text { powder }\end{array}$ & 963.16 & 161.57 & 1442.53 & 65.6 & 2.62 \\
\hline
\end{tabular}

Despite high adsorption activity, powder enterosorbents were found to be absolutely non-aggressive 
for GIT mucosa. The microphotographs demonstrate that after two-week long enterosorption session, the state of GIT of experimental animals is similar to that of intact mice. In histological structure of fundic gastric glands, villi and crypts of small intestine (duodenum), and large intestine mucosa (rectum) no pathologic alterations or abnormal inclusions were observed that evidenced on high safety and proper evacuation of the enterosorbents from an organism of experimental animals (Fig. 1).

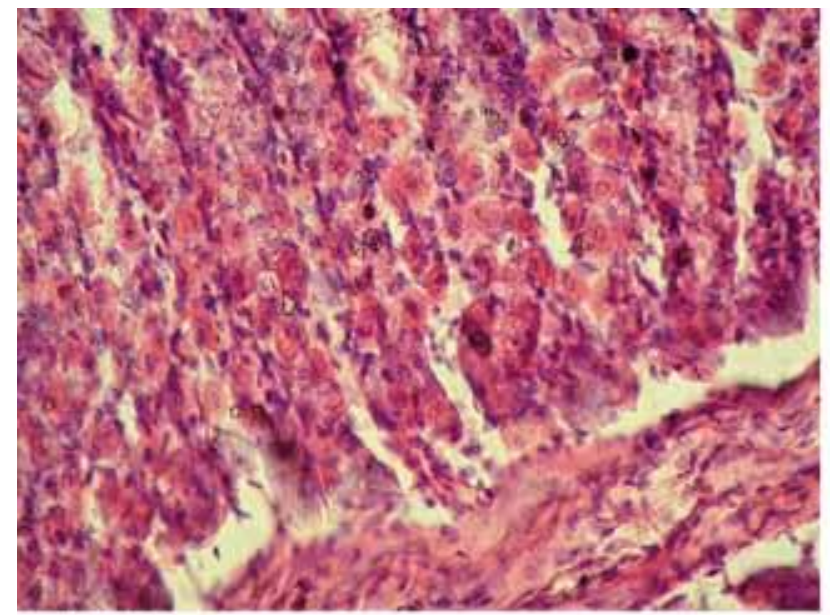

a (intact)
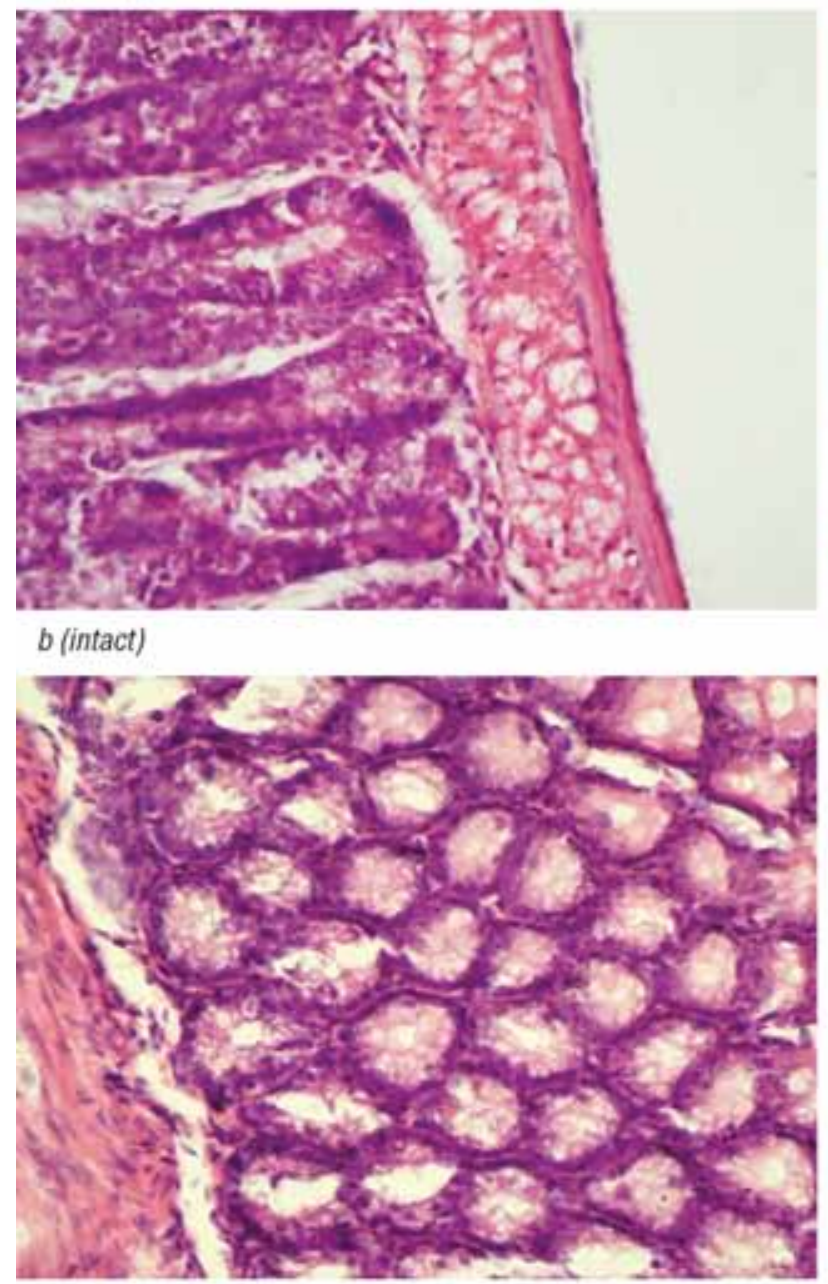

$c$ (intact)
The use of powder enterosorbent significantly influenced tumor growth dynamics in experimental animals. Starting from day 16 after tumor transplantation, in the group of animals treated with enterosorbents there has been registered a significant delay of tumor growth (Fig. 2) with the maximal antitumor effect at the $22^{\text {th }}$ day. Apart from this, 2-week session of powder enterosorbent therapy resulted in a significant metastasis suppression in mice with LLC, namely, nearly 2 -fold decrease of metastases number in enterosorption

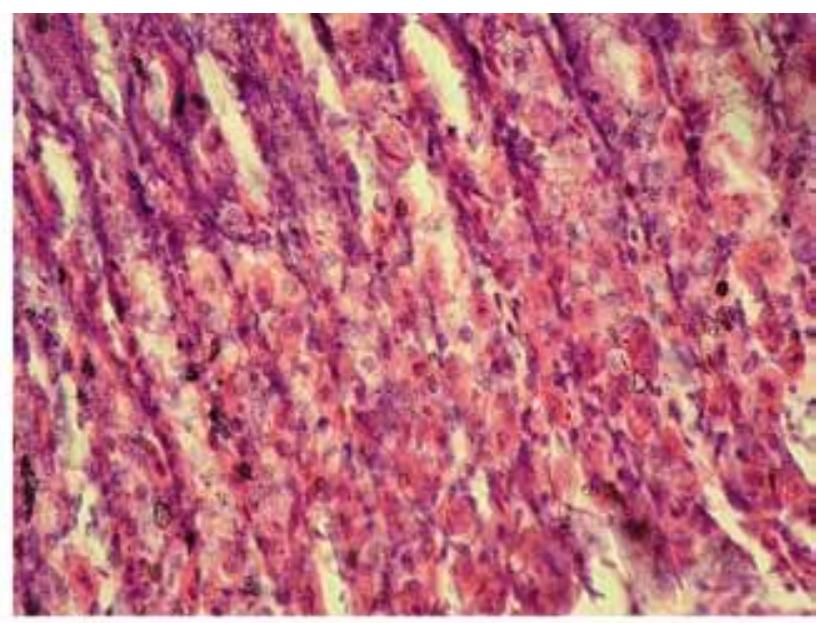

a (ES)

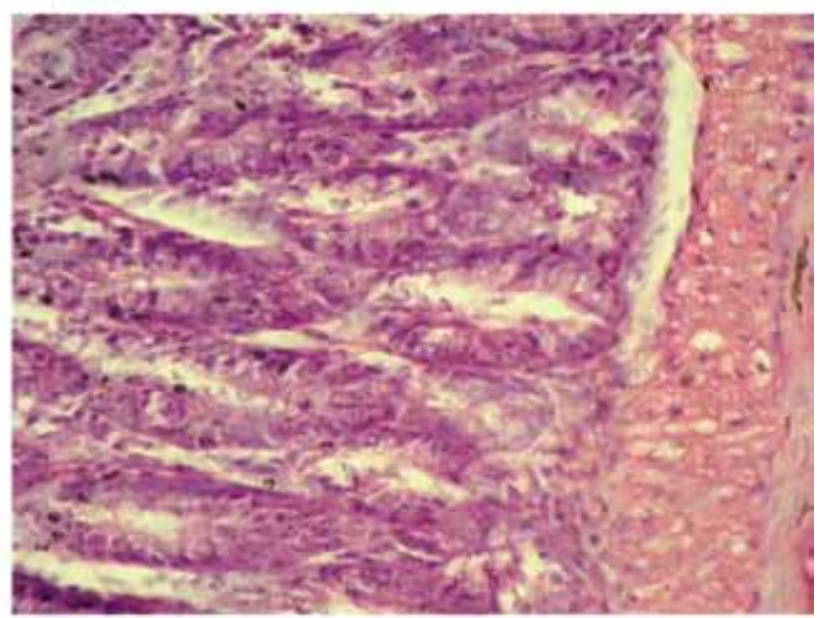

$b$ (ES)

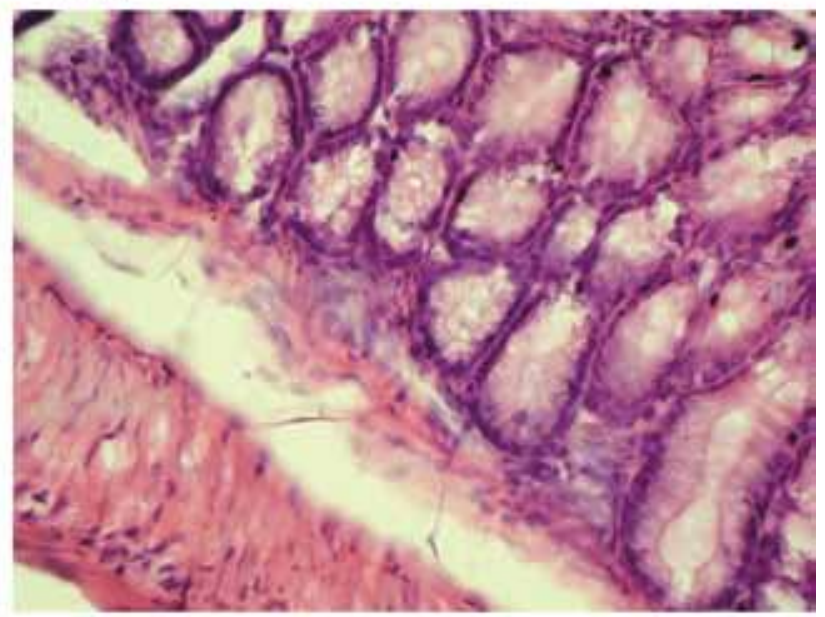

c (ES)

Fig. 1. Microphotographs of the slides of gastric fundus (a), small intestine (duodenum) (b), and large bowel (rectum) (c) of mice (on the left - intact animals, on the right - intact animals after 2-week enterosorption (ES)). Hematoxylin-eosin, $\times 400$ 
treated mice compared to the group of tumor growth control $(p<0.05)$ (Table 2).

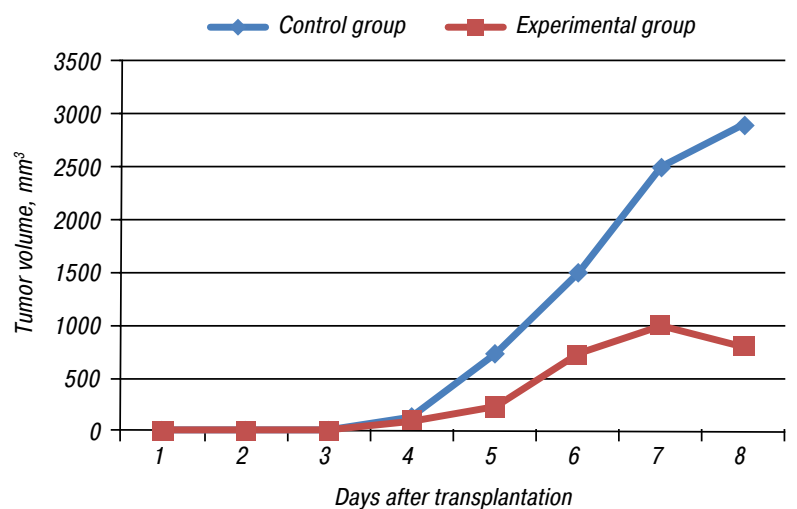

Fig. 2. Dynamics of tumor growth at the background of enterosorption

Table 2. The number and volume of metastases at day 22 after tumor transplantation

\begin{tabular}{lcc}
\hline Group of animals & Number of metastases & Volume of metastases $\left(\mathrm{mm}^{3}\right)$ \\
\hline Control mice & $10.3 \pm 1.3$ & $4.7 \pm 2.3$ \\
Enterosorption & $5.4 \pm 1.5^{\star}$ & $3.6 \pm 0.6$ \\
treated mice & & \\
\hline
\end{tabular}

Note: ${ }^{\star}$ The difference is significant compared to the control, $p<0.05$.

An absence of stimulating effect of enterosorption on metastasis volume and primary tumor volume evidenced on the safety of sorbent use in auxiliary therapy of cancer patients.

The development of LLC was accompanied with reactive changes in bone marrow (Table 3 ). There has been registered an increase of proliferative activity of erythroid line cells up to $6.00 \pm 1.15 \%$ o (vs $1.5-3 \%$ o at normal state) with simultaneous elevation of erythroid cells percent in myelogram. This effect could serve as a compensatory reaction of hemopoiesis toward anemia development in peripheral blood. After administration of physiologic solution (SF-group), the stress-related characteristic changes in bone marrow of the animals have been registered: nearly 2 -fold increase of lymphocyte counts, decrease of mature granulocyte percent (due to their efflux in peripheral circulation) along with the trend for elevation of mitotic activity of granulocyte lineage cells.

In mice with LLC treated with enterosorbent, there was observed an activation of granulocytic lineage of hemopoiesis along with significant increase of mitotic cell counts. The number of mitoses in erythroid lineage cells showed a trend for decrease while erythrocyte counts in peripheral blood increased. These data evidenced on an impairment of circulating erythrocytes (possibly of autoimmune genesis).

Regarding peripheral blood indexes of mice treated with powder eneterosorbents, the decrease of the fractions of lymphocytes and monocytes in leukograms along with significant increase of the granulocyte fraction was observed. Hemoglobin content, and platelet and erythrocyte counts elevated by 23.3 , 54.5 and $30.0 \%$, respectively. The results obtained were slightly different from these when microgranulated carbon enterosorbent was used [44].
Table 3. Influence of enterosorption on bone marrow hemopoiesis in mice with LLC

\begin{tabular}{|c|c|c|c|}
\hline Index, \% & Control group & SF-group & ES-group \\
\hline $\begin{array}{l}\text { Undifferentiated blasts } \\
\text { Neutrophilic: }\end{array}$ & 0 & 0 & $0.25 \pm 0.25$ \\
\hline jeloblasts, \% & $3 \pm$ & $67 \pm$ & 0.75 \\
\hline & & & \\
\hline & & & \\
\hline s, \% & & $17-$ & \\
\hline utrophiles, \% & $16.17 \pm$ & $.33=$ & 19.00 \\
\hline $\begin{array}{l}\text { philes, \% } \\
\text { Eosinophilic: }\end{array}$ & $10.83 \pm 2.09$ & $6.83 \pm 3.61$ & $14.12 \pm 2.11$ \\
\hline es, $\%$ & 0 & 0 & \\
\hline & & & \\
\hline$\%$ & $\perp$ & $.83 \pm$ & 0.25 \\
\hline 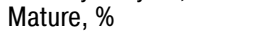 & \pm 0 & $.83 \pm$ & 0.88 \\
\hline $\begin{array}{l}\text { imature granulo- } \\
\text { tes, } \%\end{array}$ & $28.50 \pm 1.26$ & $27.5 \pm 1.61$ & $26.50 \pm 3.09$ \\
\hline ranulo- & $28.83 \pm 8.14$ & $18.0 \pm 7.81$ & $34.00 \pm 3.67$ \\
\hline ulocytes, $\%$ & 57.3 & 45.5 & 60.5 \\
\hline & & & \\
\hline es, $\%$ & $1.00 \pm 0.58$ & $67+$ & \\
\hline 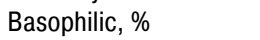 & 0 & $7.33=$ & 3.6 \\
\hline & & & \\
\hline & & & \\
\hline id cells & 2 & .5 & 28.75 \\
\hline Myel & $1.66 \pm 0.69$ & $1.45 \pm 0.44$ & $2.38 \pm 0.50$ \\
\hline$\%$ & $0.50 \pm 0$ & $1.17 \pm$ & 0.25 \\
\hline & & $18.17 \pm 5.0$ & $11.25 \pm 1.93$ \\
\hline & +0 & 0 & \\
\hline$\%$ & $12 \pm 0$ & 0 & 0.12 \\
\hline ryocytes, \%o & 0 & 0 & 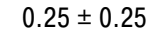 \\
\hline Mitotic index of red & $6.00 \pm 1.15$ & 2.06 & $3.00 \pm 1.00$ \\
\hline M & 2 & 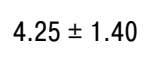 & $3.00 \pm 3.51^{*}$ \\
\hline Total & $00 \pm 1$ & $11.00 \pm 1.73$ & $16.00 \pm 4.04^{*}$ \\
\hline
\end{tabular}

Note: ${ }^{*}$ The difference is significant compared with group $1, p<0.05$.

Apart from increased erythrocyte counts, in peripheral blood of mice with LLC after enterosorption session we have revealed an increase of osmotic resistance of erythrocyte membranes and partial restoration of their acceptor function registered by binding with vital dye methylene blue (Fig. 3).

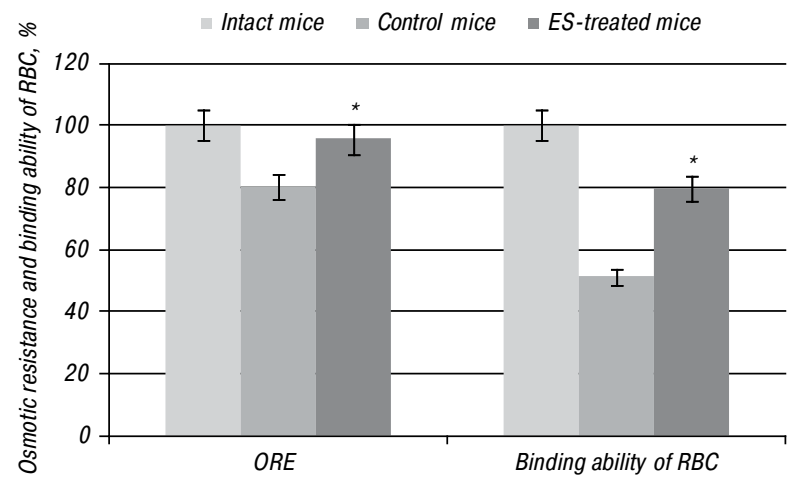

Fig. 3. Indexes of osmotic resistance of erythrocytes (ORE) and their binding capacity by vital dye methylene blue in the groups of intact, control and enterosorption-treated mice. ${ }^{*} p<0.05$ compared with control mice. RBC - red blood cells

Earlier it has been shown that despite an absence of systemic pharmacokinetics, enterosorbents could significantly decrease the toxic loading on kidney and liver. It is especially important in the situations if barrier function of intestinal epithelium is weakened, while the presence of highly active enterosorbents in intestines serves as an artificial barrier against 
the passage of an increased quantities of intestinal metabolic products, bacterial endotoxins and microflora, into the circulation [46-48]. As the result of such functional "time-out" in detoxification organs, here are "launched" the natural regenerative processes [49-51], that finally lead to the decrease of endogenous detoxification degree [46, 52-54].

In LLC-bearing mice, in the morphology of kidneys and liver that are the organs not affected by metastasis, there were observed multiple degenerative alterations, which were, possibly, caused by manifestations of PNS [55]. For example, on the slices of kidneys of animals from group 1 (tumor growth control) (Fig. 4, a, 1-2) one may see the tubules with evidence on a protein dystrophy of various degree, especially in convoluted tubules of cortex. In cytoplasm of nephrocytes of convoluted tubules there appeared hyaline-like protein globules and droplets that may merge with each other and fill all the cell. There were detected some tubules with necrobiosis - necrosis of separate epitheliocytes. Glomeruli were at the state of moderate atrophy of various degree. At the same time, there could be seen atrophic tubules of medulla with dramatically flattened epithelium, which contain eosinophilic masses, lymphoid cells chambers.

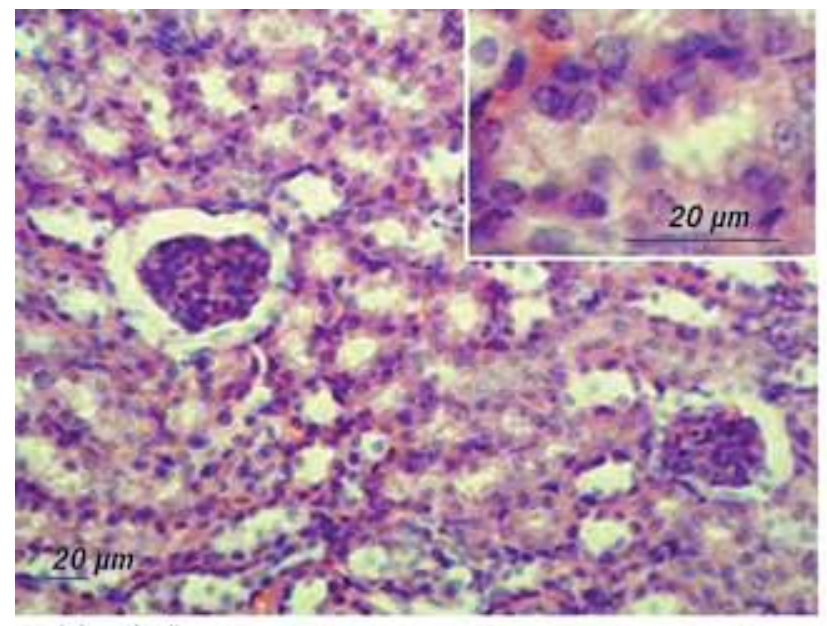

at (cortical)

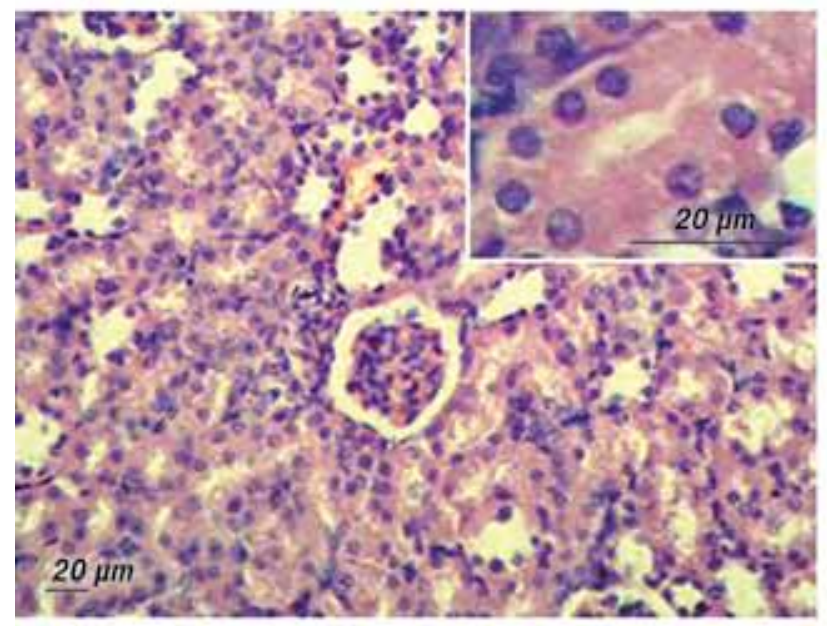

b3 (cortical)
After enterosorption (Fig. 4, $b, 3-4$ ) the functional state of kidneys became notably normalized. The structure of renal cortical cells was better preserved, compared to the control group. Cytoplasm of the majority of epitheliocytes was homogenous, more acidophilic, the lumen of the tubules was moderate, however, in some tubules one could observe insignificant destructive changes of epitheliocytes.

Along with positive morphologic alterations in the kidneys of animals under the influence of enterosorbents with potent regenerative potential, their functional activity was significantly improved: the concentration of uric acid and creatinine in blood plasma decreased notably, and urea content approached the values in the group of intact mice (Fig. 5). The content of "medium molecules" in blood plasma (integral index of EGI) decreased by $32.5 \%$.

The indexes of liver function in enterosorbenttreated animals did not go beyond the norm, too. Enterosorption caused significant decrease of ALT and AST activities (by 22.3 and $13.0 \%$, respectively), total bilirubin content by $12.5 \%$, AlkP by $5.4 \%$, compared to the control group of tumor-bearing mice (Fig. 6).

After enterosorption session, the state of histologic structure of liver parenchyma became significantly improved: quite clear radially directed hepatic
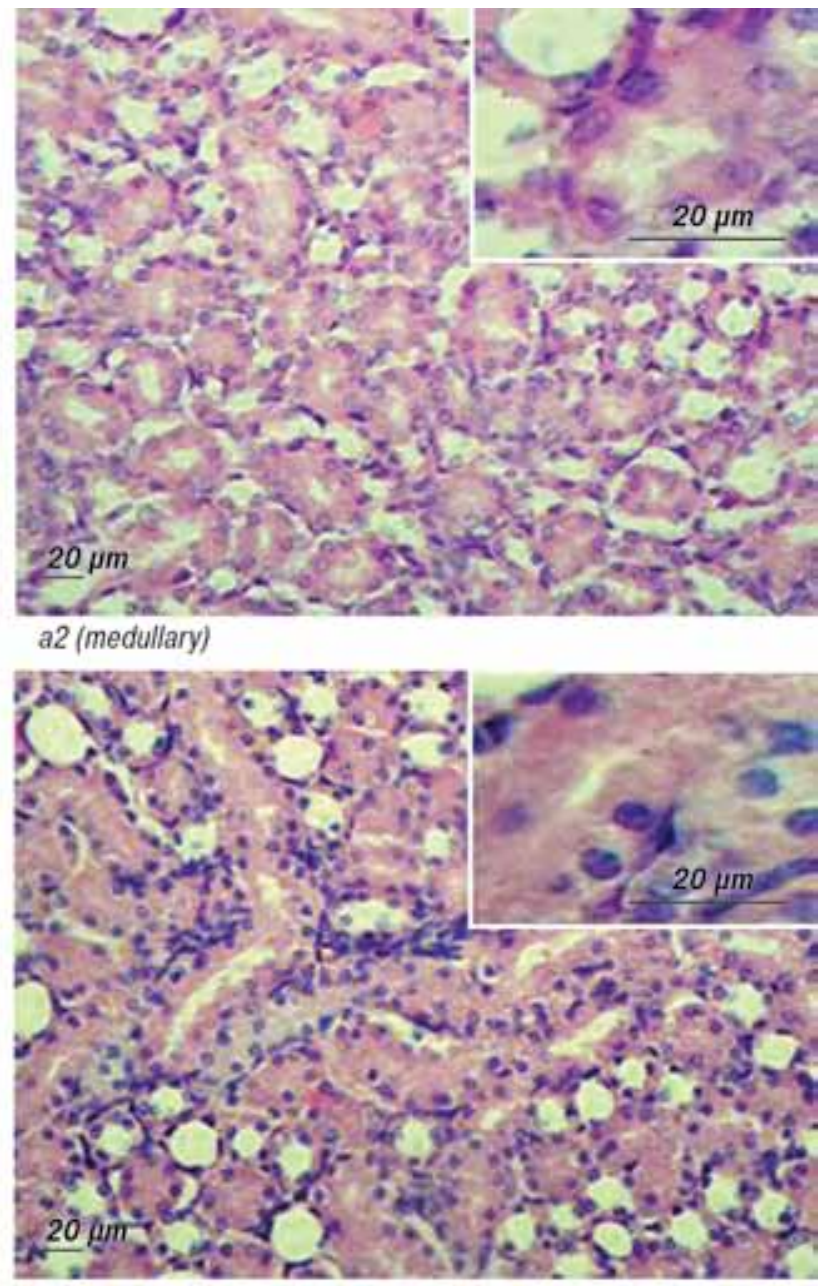

b4 (medullary)

Fig. 4. Microphotographs of murine kidney sections: $a$ - control mice; $b$ - enterosorption-treated mice. Cortical $(1,3)$ and medullary $(2,4)$ substances. Hematoxylin-eosin, $\times 400$ 


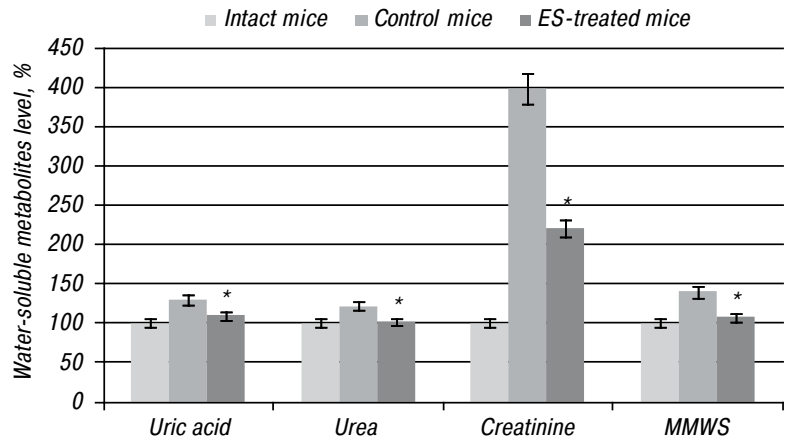

Fig. 5. The content of water-soluble uremic toxins and "median molecules" in the groups of intact, control, and enterosorption-treated mice. ${ }^{\star} p<0.05$ compared with control mice. MMWS - middle molecular weight substances

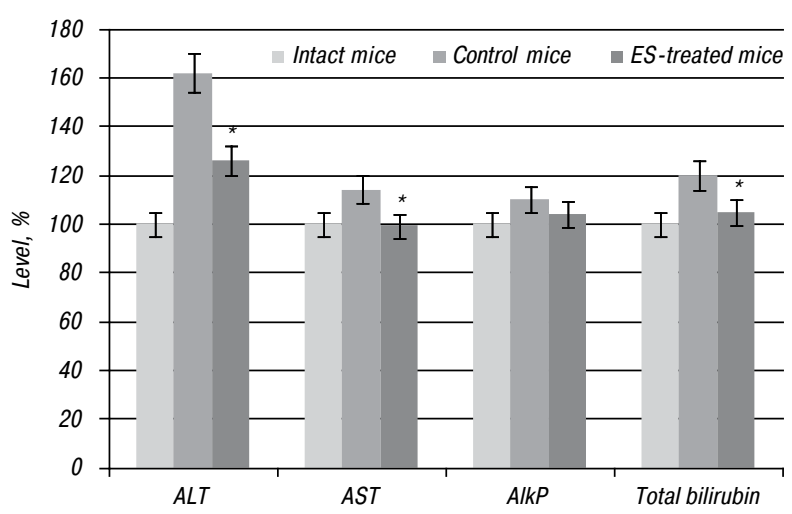

Fig. 6. Indexes of cytolysis and cholestasis in the groups of intact, control, and enterosorption-treated mice. ${ }^{*} p<0.05 \mathrm{com}$ pared with control mice

trabeculae, moderately widened perisinusoidal spaces, hepatocytes of polygonal form, with clear round nuclei, nucleoli, and chromatine lumps were registered (Fig. 7). The observed elevated basophilism of the cytoplasm evidenced on the restoration of protein synthesis in liver. This was supported by an increased content of total protein and albumin by $16 \%$ and nearly $20 \%$ in the group of ES-mice compared to the control group.

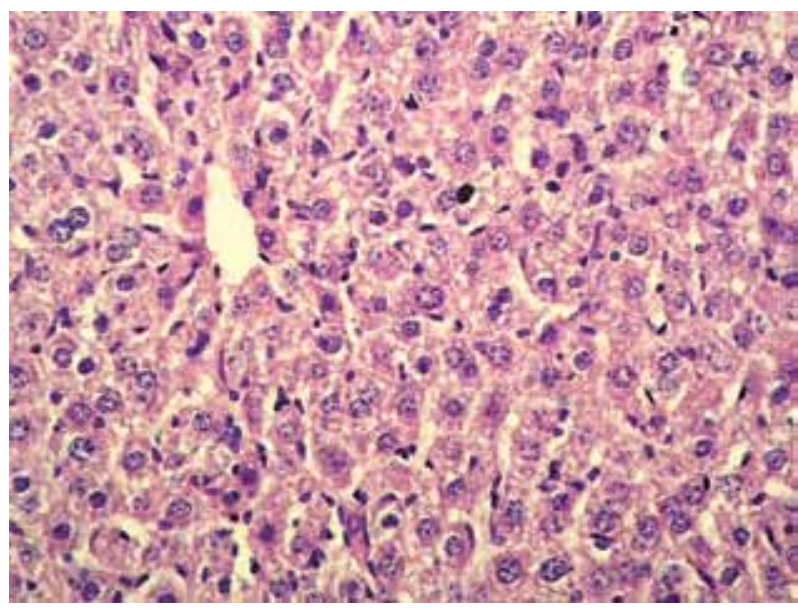

Fig. 7. Microphotographs of liver sections of enterosorptiontreated mice. Hematoxylin-eosin, $\times 400$

One should note that apart from the concentration index, the most important index is the content of "effective" protein fraction, i.e. the fraction with restored transporting properties. However, in oncologic patients an oxidative modification of proteins which occurs upon the influence of reactive oxygen species often prevents normal functioning of the proteins. An intensity of this process is predetermined by amino acid composition of particular proteins and could be considered as an early marker of oxidative stress. Oxidative stress is accompanied with an increased level of the products of excessive lipid peroxidation, AOPP, suppression of endogenous antioxidant defense (AOD) and, consequently, increased level of EGl.

The depletion of AOD reserves was reflected in the decreased activities of SOD and catalase in blood serum by 69.0 and $34.5 \%$, respectively, and decreased content of reduced glutathione (by $20.9 \%$ ) compared to intact animals (Fig. 8, a). The characteristic reaction of a body toward development of oxidative stress was an increased (compared to intact animals) blood serum levels of lipid hydroperoxide (LHP), MDA, AOPP, and IMA by $179,61.54,121.02$ and $111.6 \%$, respectively (Fig. 8, b).
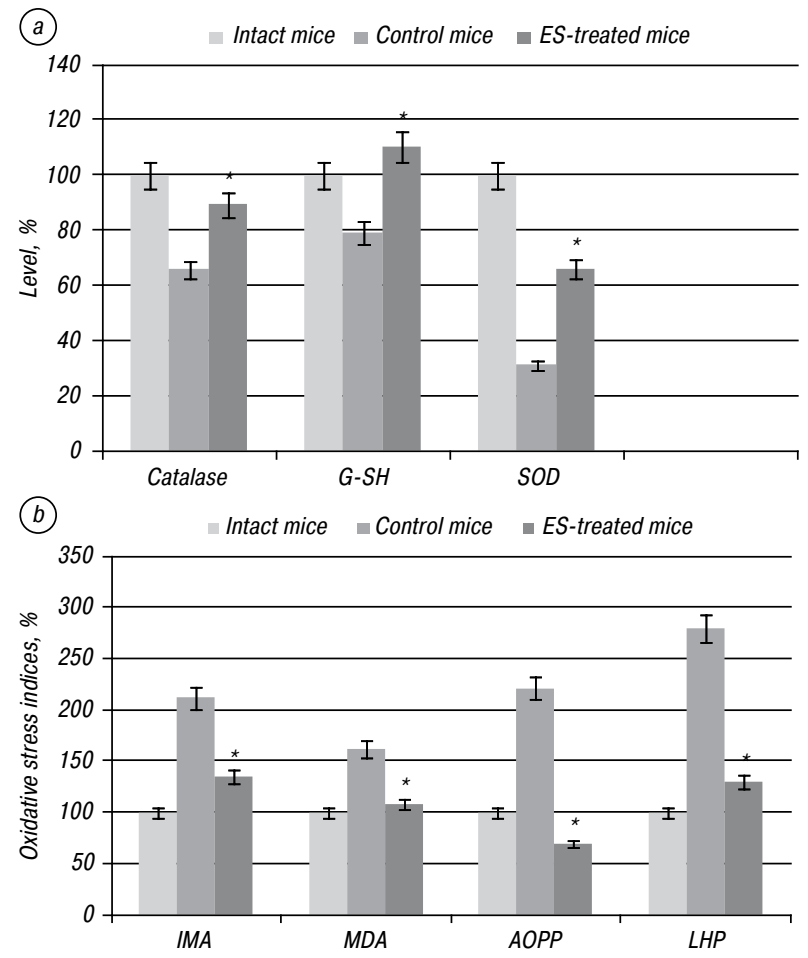

Fig. 8. Indexes of AOD $(a)$ and oxidant stress $(b)$ in the groups of intact, control, and enterosorption-treated mice. ${ }^{*} p<0.05$ compared with control mice

Enterosorption exerted an expressed positive effect on a pro-oxidant-antioxidant balance. So, the content of MDA, IMA, AOPP, and LHP in ES-group decreased by $53.85,76.72,152.79$ and $149.0 \%$, respectively, compared to the control group of animals. Also, there was observed a significant activation of AOD: the activities of SOD and catalase, the major scavengers of free radicals and oxygen metabolites, and the main protectors of proteins, DNA, and cell membranes at the conditions of oxidative stress, increased by 35.0 and $23.8 \%$, respectively, while the level of reduced glutathione increased by $30.9 \%$ (Fig. 8).

In recent years, the IMA index is considered as an oxidative stress marker along with the common indexes at different pathological states. Its increase 
in the group of control mice with LLC compared to intact animals (from 0.064 to 0.136 abs. u.) evidenced on disturbed structure of binding region of blood serum albumin in these animals and, consequently, on its decreased capability for cobalt binding. After administration of enterosorbent the decrease of this index to the value of 0.088 abs was observed, indicating a partial restoration of the structural-functional characteristics of albumin due to the decrease of its ligand loading. This hypothesis was supported in the study of thermodenaturation of blood serum of mice from control, ES-treated and intact groups. The corresponding melting curves of plasma samples are presented in Fig. 9. The main maximums of thermodenaturation endotherm belong to albumin fraction. The higher melting temperatures point on an increased ligand loading of albumin, while the shape of endotherms reflects the changes of its native conformation [56]. The melting temperature of blood plasma proteins of mice in ES-group decreased from 72 to $68^{\circ} \mathrm{C}$, along with some moderate positive changes in the shape of thermodenaturation curve.

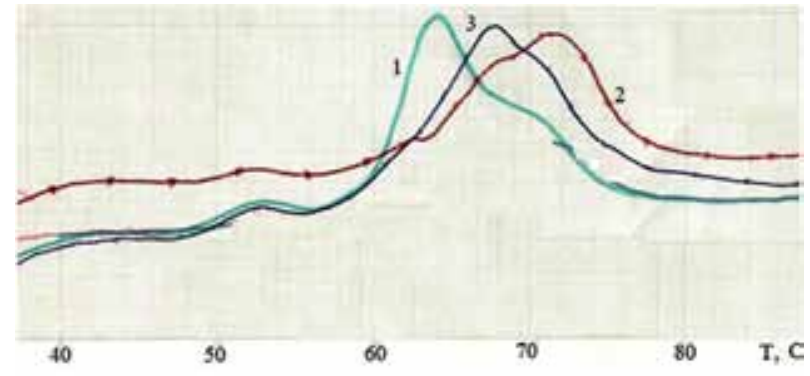

Fig. 9. Original thermograms of blood plasma of mice: intact group (1), control group (2), and ES-treated group (3)

The results obtained by the method of DSC, demonstrate the noticeable deliganding the albumin molecule and partial normalization of its "morphology" after the enterosorption course.

In conclusion, the two-week long enterosorption session in mice with LLC caused the suppression of tumor growth and metastasis, weakening the manifestations of anemia and significant normalization of bone marrow hemopoiesis. Enterosorption exerted a positive influence on the structural-morphologic indexes and regenerative potential of kidneys and liver, mitigated manifestations of oxidative stress, decreased the level of EGI, promoted deliganding of albumin molecule and deloading of erythrocyte membranes.

\section{REFERENCES}

1. Starikov AV, Diagil' IS, Cherviakova EV, et al. Enterosorption and therapeutic plasmapheresis in the intensive therapy of patients with acute leukemia and of persons who were victims of the accident at the Chernobyl Atomic Electric Power Station. Lik Sprava 1994; 9-12: 43-6 (in Russian).

2. Nikolaev VG, Ryabov SI, Pyrig LA, et al. Unconventional methods of activated charcoal application in chronic renal disease therapy. Nefrologia Mexicana 1985; 6: 148.

3. Frolov VM, Sotskaia IaA, Peresadin NA, et al. Efficiency of enterosorbent white coal in the treatment of patients with hepatic cirrhosis. Lik Sprava 2012; 8: 108-15 (in Russian).
4. Sukhov UA, Gebesh VV. The influence of enterosorption on the content of proinflammatory cytokines in intestinal infection and measles. Clin Immunol 2007; 1: 24-33 (in Russian).

5. Nikolaev VG. Enterosgel. Kyiv: Bogdana, 2009; 159 p. (in Russian).

6. Vorontsova EM, Mashkov OA. Effect of enterosorption on the course of psoriasis. Ter Arch 1991; 63: 82-4 (in Russian).

7. Uchaikin VF, Novokshonov AA, Sokolova NV, et al. The place and significance of enterosorption in the etiopathogenetic therapy of acute intestinal infections in children. Pediatrics 2007; 2: 44-50 (in Russian).

8. Shevchuk OO, Posokhova EA, Sakhno LA, et al. Theoretical ground for adsorptive therapy of anthracyclines cardiotoxicity. Exp Oncol 2012; 34: 314-22.

9. Shostka GD, Ryabov SI, Lukichev BG, et al. Oral sorbents in the treatment of chronic renal failure. Ther Arch 1984; 56: 58-63 (in Russian).

10. Shevchuk OO, Posokhova KA, Todor IN, et al. Prevention of myelosuppression by combined treatment with enterosorbent and granulocyte colony-stimulating factor. Exp Oncol 2015; 37: 135-8.

11. Shevchuk OO, Bodnar YY, Bardakhivskaya KI, et al. Enterosorption combined with granulocyte colony stimulating factor decreases melphalan gonadal toxicity. Exp Oncol 2016; 38: 172-5.

12. Xue Y, Chen F, Zhang D, et al. Tumor-derived VEGF modulates hematopoiesis. J Angiogenes Res 2009; 1: 9.

13. Suzuki KM, Aiba K, Hatake K. Rapid progression of anemia related to tumor-lysis syndrome associated with bortezomib treatment in myeloma patients. Jpn J Clin Oncol 2014; 44: 435-41.

14. Jurado Gámez B, García de Lucas MD, Gudín Rodríguez M. Lung cancer and paraneoplastic syndromes. An Med Interna 2001; 8: 44046 (in Spanish).

15. Tas F, Eralp Y, Basaran M, et al. Anaemia in oncology practice: relation to diseases and their therapies. Am J Clin Oncol 2004; 2: 11-26.

16. Caro JJ, Salas M, Ward A, et al. Anemia as an independent prognostic factor for survival in patients with cancer: a systemic, quantitative review. Cancer 2001; 91: 2214-21.

17. Nikolaev VG, Sakhno LA, Snezhkova EA, et al. Carbon adsorbents in oncology: achievements and perspectives. Exp Oncol 2011; 33: 2-8.

18. Muravskaya GV, Nikolaev VG, Sergeev VP, et al. Enterosorption in oncotherapy. Biomater Artif Cells Immobilization Biotechnol 1991; 19: 167-74.

19. Sakhno LA, Nikolaev VG. Sorption methods in oncology. Oncologiya 1999; 3: 165-76 (in Russian).

20. Meloni M, Nicolay JF. Dynamic monitoring of glutathione redox status in UV-B irradiated reconstituted epidermis: effect of antioxidant activity on skin homeostasis. Toxicol In Vitro 2003; 17: 609-13.

21. Jones RH, Hothersall JS. The effect of diabetes and dietary ascorbate supplementation on the oxidative modification of rat lens beta L crystallin. Biochem Med Metab Biol 1993; 50: 197-209.

22. Shubbar E, Vegfors J, Carlström M, et al. Psoriasin (S100A7) increases the expression of ROS and VEGF and acts through RAGE to promote endothelial cell proliferation. Breast Cancer Res Treat 2012; 134: 71-80.

23. Taverne YJ, Bogers AJ, Duncker DJ, et al. Reactive oxygen species and the cardiovascular system. Oxid Med Cell Longev 2013; 2013: 862423.

24. Cribbs DH, Azizeh BY, Cotman CW, et al. Fibril formation and neurotoxicity by a herpes simplex virus glycoprotein 
B fragment with homology to the Alzheimer's A beta peptide. Biochemistry 2000; 39: 5988-94.

25. O'Brien RC, Luo M. The effects of gliclazide and other sulfonylureas on low-density lipoprotein oxidation in vitro. Metabolism 1997; 46: 22-5.

26. Peters T Jr. Serum albumin. Adv Protein Chem 1985; 37: $161-245$.

27. Anraku M, Chuang VT, Maruyama T, et al. Redox properties of serum albumin. Biochim Biophys Acta 2013; 1830: $5465-72$.

28. Fiorillo C, Batignani G, Pavoni V, et al. Albumin Cys34 adducted by acrolein as a marker of oxidative stress in ischemia-reperfusion injury during hepatectomy. Free Radic Res 2016; 50: 831-9.

29. Shevchuk OO, Posokhova KA, Sidorenko AS, et al. The influence of enterosorption on some haematological and biochemical indices of the normal rats after single injection of melphalan. Exp Oncol 2014; 36: 94-100.

30. Nikolaev VG. Sorption therapy with the use of activated carbons: effects on regeneration of organs and tissues. In: TMS Chang, Y Endo, VG Nikolaev, T Tani, Y Yu, eds. Hemoperfusion, plasmaperfusion and other clinical uses of general, biospecific, immuno and leucocyte adsorbents. W: H. Zheng, 2017: 221-43.

31. Siewinski M, Saleh Y, Gryboc M, et al. Determination of cysteine peptidases-like activity and their inhibitors in the serum of patients with ovarian cancer treated by conventional chemotherapy and vitamin E. J Exp Ther Oncol 2004; 4: 189-93.

32. Gasparre G, Porcelli AM, Lenaz G, et al. Relevance of mitochondrial genetics and metabolism in cancer development. Cold Spring Harb Perspect Biol 2013; 5: pii: a011411.

33. Kellar A, Egan C, Morris D. Preclinical murine models for lung cancer: clinical trial applications. Bio Med Research Int 2015; 2015: 1-17.

34. Sarnatskaya VV, Nikolaev VG, Yushko LA, et al. Effect of enterosorption on paraneoplastic syndrome manifestations in mice with highly angiogenic variant of Lewis lung carcinoma. Exp Oncol 2015; 37: 255-61.

35. Rodionova NK. The dynamics of proliferation and differentiation of osteogenic cells under supportive unloading. Tsitol Genet 2011; 45: 22-7.

36. Gavrilov VB, Mishkorudnaya MI. Spectrophotometric determination of the content of lipid hydroperoxides in blood plasma. Lab Delo 1983; 3: 33-5 (in Russian).

37. Chang D, Sha Q, Zhang X, Liu P, et al. The evaluation of the oxidative stress parameters in patients with primary angle-closure glaucoma. PLoS One 2011; 6: e27218.

38. Witko-Sarsat V, Friedlander $M$, Capeillère-Blandin $C$, et al. Advanced oxidation protein products as a novel marker of oxidative stress in uremia. Kidney Int 1996; 49: 1304-13.

39. Bar-Or D, Lau E, Winkler JV. A novel assay for cobalt-albumin binding and its potential as a marker for myocardial ischemia - a preliminary report. J Emerg Med 2000; 19: 311-5.

40. Laboratory methods in the clinic. VV Menshikov, ed. Moscow: Meditsina, 1987: 119-20 (in Russian).
41. Togaibaev AA, Kurguzkin AV, Rikun IV, et al. A method of diagnosing endogenous poisoning. Lab Delo 1988; 9: 22-4 (in Russian).

42. Korolyuk MA, Ivanova LI, Mayorova IG, et al. Method for determining catalase activity. Lab Delo 1988; 1: 16-9 (in Russian).

43. Chevara S, Chaba I. Székei I. The role of superoxide dismutase in the oxidative processes of the cell and the method of its determination in biological materials. Lab Delo 1985; 11: 678-81 (in Russian).

44. Sarnatskaya VV, Sidorenko AS, Klymchuk DA, et al. Optimization of physico-chemical properties of carbon enterosorbents and evaluation of their sorption activity for use in the treatment of paraneoplastic syndrome and other endogenous intoxications in cancer patients. Exp Oncol 2013; 35: 83-8.

45. Bardakhivska KI, Sakhno LA, Kopcha VS, et al. Practical recommendations on the use of granulated carbon enterosorbents «Carboline». VG Nikolaev, MA Andreychin, eds. Kyiv: Diva Ltd, 2013. 28 p.

46. Nikolayev VG, Mikhalovsky SV, Gurina NM, et al. Modern enterosorbents and mechanisms of their action. Efferent Ther 2005; 11: 3-17 (in Russian).

47. Belyakov NA, Solomennikov AV, Zhuravleva IN, et al. Enterosorption - mechanisms of therapeutic action. Efferent Ther 1997; 3: 20-6 (in Russian).

48. Nikolaev VG, Mikhalovsky SV, Nikolaeva VV, et al. Enterosorption: the state of the issue and prospects for the future. Visnik Probl Biol Med 2007; 4: 7-17 (in Russian).

49. Vozianova ZhI. Enterosorption in complex treatment of patients with viral hepatitis. Vrachebnoe Delo 1990; 4: 117-20 (in Russian).

50. Mosunov AI, Pozdnyakov AV. Clinical study of the effectiveness of Enterosgel preparation for diffuse liver pathology accompanied by hepatodepressive syndrome. In: Enterosgel, Enterosorption Technologies in Medicine. Novosibirsk: Moscow, 1999: 15-8 (in Russian).

51. Moroz LV, Paliy IG, Tkachenko TV. Carried out drug Enterosgel in complex therapies of the sickness on the state of the art of hepatitis is the suppressive dysbacteriosis of the intestine. Nova Medicine 2005; 1: 72-4 (in Russian).

52. Andreichin MA, Nikolayev VG, Yosik YI. Therapeutic efficacy of enterosgel in acute respiratory infections. Infect Diseases 2011; 1: 25-28 (in Russian).

53. Osadchaya OI. The role of enterosorbtion in the treatment of metabolic intoxication in patients with severe burns. Med Ukr 2008; 7: 56-8 (in Russian).

54. Osadchaya OI, Boyarskaya AM, Sheiman BS, et al. Influence of enterosorption on the content of pro- and antiinflammatory cytokines in severe thermal trauma. Med Urg Conditions 2008; 3: 74-6 (in Russian).

55. Mathew DG, Rooban T, Janani V, et al. Review of paraneoplastic syndromes associated with oropharyngeal squamous cell carcinoma. J Oral Maxillofac Pathol 2010; 14: 41-7.

56. Sarnatskaya VV, Lindup WE, Niwa T, et al. Effect of protein-bound uraemic toxins on the thermodynamic characteristics of human albumin. Biochem Pharmacol 2002; 63: 1287-96. 